\title{
ACTION OF ORGANIC MATTER ON SILVER SALTS.
}

By WM. Ripley Niohols.

Mass. Inst. Technology, Boston.

In the March number of The Analyst occurs a paper " On the Action of Organic Matter on Silver Salts," by Henry Leffman, M.D., Microscopist to the Pennsylvania State Board of Agriculture. In this article occurs the rather remarkable statement: "The action of organic matter upon silver salts is well known, but $I$ am not aware of any attempts to atilize this method for the examination of water."

Although less commonly employed than the chloride of gold, nitrate of silver has long been used, and is still frequently used, as a qualitative test for organic matter in water. That it was the custom to apply this test forty and fifty years ago, appears from the water reports of 1830-40. For example, I have in my hand at the moment a report of Dr. C. T. Jackson, dated July 1, 1834, and Silliman's Report on the Analysis of the Waters, dated October 29,1845 , in both of which the test is used without special remark. When the test was first used I do not know. Glauber knew that nitrate of silver would blacken hard wood so as to make it look like ebony, and would also colour hair, feathers, \&c. (Mirac. Mundi Explic., Amsterdam, 1656, p. 44.) In a number of mineral water analyses reported between 1750 and 1800, the nitrate of silver seems to have been used merely as a test for chlorides ; but in Baumé's Chymie Expérimentale (Paris 1773), nitrate of silver is used to see whether a mineral water contains any "principe phlogistique ou sulfureux" : if the precipitate is white, it is a sign that the water is not charged with " matière inflammable."

Coming to later times, the author of the paper alluded to ignores utterly Fleck's method for the quantitative use of the test, and for distinguishing thereby between what he designates as "Moderstoffe" and "Fäulnissstoffe." Fleck's method was first published in the Journal fur Prakt. Chemie, iv. (1871), p. 364, and is given in Tiemann's Anleitung zur Untersuchung von Wasser. Fleck has published the results of the examination of a considerable number of samples of water by this method in the various annual reports of the Chemische Centralstelle, in Dresden. Although this method has not been used to a very great extent except by its originator, it is, I presume, well known to water analysts. 


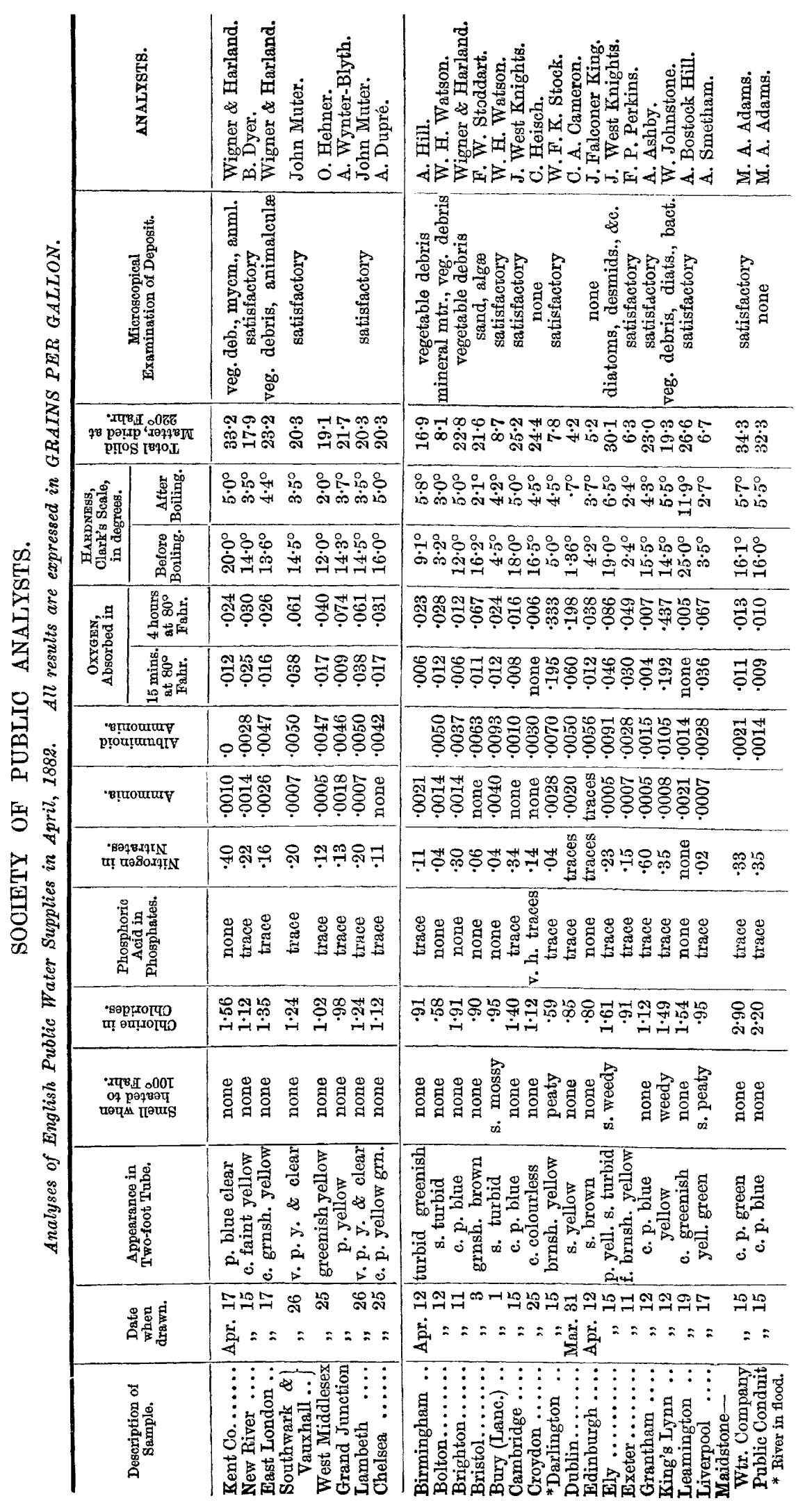




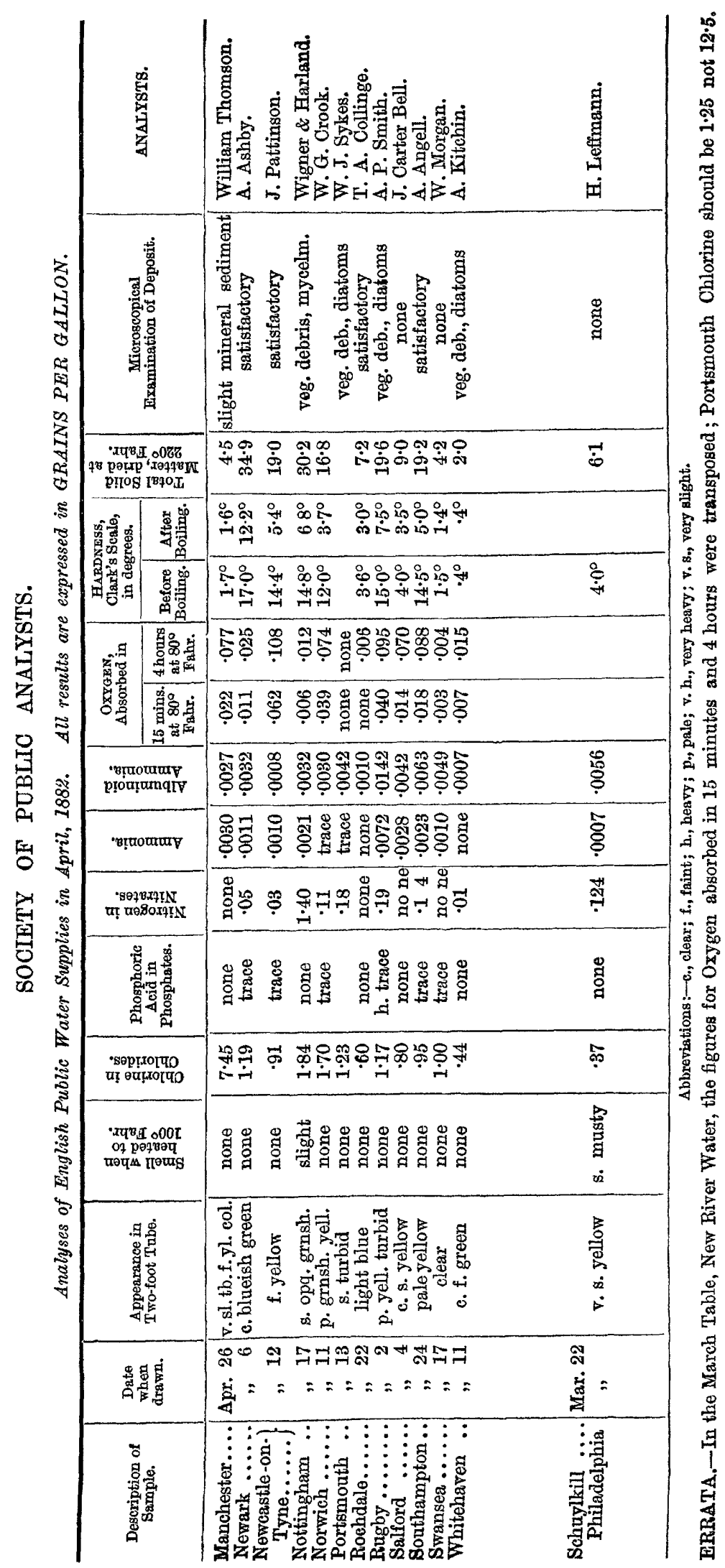

